\title{
The neutrophil to lymphocyte ratio is associated with severity of rheumatic mitral valve stenosis
}

\author{
This article was published in the following Dove Press journal: \\ Journal of Blood Medicine \\ 13 May 2015 \\ Number of times this article has been viewed
}

\section{Erkan Baysal' \\ Cengiz Burak ${ }^{2}$ \\ Serkan Cay ${ }^{2}$ \\ Tolga Aksu \\ Bernas Altıntaș' \\ Barıș Yaylak' \\ Utkan Sevük ${ }^{4}$ \\ Önder Bilge'}

'Department of Cardiology, Diyarbakır Gazi Yașargil Education and Research Hospital, Diyarbakır, Turkey; ${ }^{2}$ Department of Cardiology, Ankara Yüksek İhtisas Education and Research Hospital, Ankara,

Turkey; ${ }^{3}$ Department of Cardiology, Kocaeli Derince Education and Research Hospital, Kocaeli, Turkey; ${ }^{4}$ Department of Cardiovascular Surgery, Diyarbakır Gazi Yașargil Education and Research Hospital, Diyarbakır, Turkey
Correspondence: Erkan Baysal Fabrika Mahallesi 813. Sokak no:I, Altınpark sitesi $C$ blok no:2I yenișehir, 21090, Diyarbakır, Turkey

Tel +905317906499

Email dr.erkan.baysal@hotmail.com
Background: Rheumatic heart disease (RHD) is a serious health concern in developing countries. Rheumatic mitral stenosis (RMS) is the most long-term sequel in RHD. The neutrophil to lymphocyte ratio (NLR) is a novel marker, and a higher NLR has been associated with poor clinical outcomes in various cardiovascular disorders. We evaluated the availability of NLR to predict severity of mitral stenosis (MS) in patients with RHD.

Methods: We analyzed 300 consecutive patients with RMS. The patients were divided into tertiles according to NLR: $0.85<\mathrm{NLR} \leq 1.85$ ( $\mathrm{n}=100$, tertile 1$), 1.86 \leq \mathrm{NLR} \leq 2.46(\mathrm{n}=100$, tertile 2 ), and $2.47 \leq$ NLR $\leq 7.08$ ( $n=100$, tertile 3 ). Patients with RMS were divided into three groups based on the degree of MS as mild, moderate, and severe MS. After the initial evaluation, 187 patients with moderate-to-severe RMS (Group 1) and 113 patients with mild RMS (Group 2) were reassessed.

Results: The patients with severe RMS had significantly elevated NLR, mean platelet volume, and pulmonary artery systolic pressure values compared to patients with moderate and mild MS $(P<0.001, P<0.001, P<0.001$ respectively). Multivariate binary logistic regression analysis revealed that high levels of NLR was an independent predictor of severe RMS (odds ratio $=0.68$, $P=0.008$ ). Moderate-to-severe RMS incidence was significantly higher among patients in the tertile 3 (odds ratio $=2.8, P=0.001$ ).

Conclusion: NLR is a new inflammatory marker and a simple, rapid, and easily accessible prognostic parameter that can be associated with severity of RMS in patients with RHD.

Keywords: rheumatic heart disease, rheumatic mitral stenosis, neutrophil to lymphocyte ratio

\section{Introduction}

Rheumatic heart disease (RHD) is a chronic acquired heart disorder resulting from acute rheumatic fever (ARF). Although rare in developed countries, RHD continues to be a major cause of cardiac morbidity and mortality among children and young adults in the developing countries. ${ }^{1,2}$ So far about 15 million cases of RHD are reported worldwide, with 282,000 new cases and 233,000 deaths occurring annually. ${ }^{3}$ RHD is more common in females. ${ }^{4}$ Although ARF causes pancarditis, it primarily affects the endocardium and repeated episodes of autoimmune reactions cause chronic inflammation in the valvular apparatus. Rheumatic mitral stenosis (RMS) is a common manifestation of RHD.

While the pathophysiology has not been fully understood, it is postulated that inflammatory response is the most important part of the pathogenesis of RHD. ${ }^{5,6}$ The total white blood cell count is an easy, inexpensive, and widely available means of 
detecting inflammation. Neutrophils are the major components of leukocytes in peripheral blood. The neutrophil to lymphocyte ratio (NLR) was recently reported to be a marker of thrombosis and inflammation and was found to be associated with the severity and prognosis of several cardiovascular diseases. $^{7-9}$

The aim of this study was to evaluate the relationship between NLR and the degree of RMS.

\section{Methods}

\section{Study population}

This multicenter retrospective study included 300 mitral stenosis (MS) patients who had been admitted to the Department of Cardiology at the Diyarbakır Gazi Yaşargil Education and Research Hospital in Diyarbakır and Ankara Yüksek İhtisas Education and Research Hospital in Ankara, from January 2013 to June 2014. All the patients underwent a clinical examination, ECG, and transthoracic echocardiography. Patients with diabetes mellitus, hypertension, malnutrition, coronary artery disease, acute corticosteroids use, acute infection, chronic renal and hepatic disease, and hematological disease were excluded from the study.

The patients were divided into tertiles according to NLR: $0.85<$ NLR $\leq 1.85(\mathrm{n}=100), 1.86 \leq \mathrm{NLR} \leq 2.46$ $(n=100)$, and $2.47 \leq$ NLR $\leq 7.08(n=100)$. Patients with RMS were divided into three groups based on the degree of MS as mild, moderate, and severe RMS. Valve disease severity was defined according to the American Society of Echocardiography and American College of Cardiology/ American Heart Association guidelines for the management of valvular heart disease. ${ }^{10}$ Venous peripheral blood samples were taken on admission. Blood samples were drawn into standardized tubes containing dipotassium ethylenediaminetetraacetic acid (EDTA) and delivered to the laboratory within a few minutes. All hematological measurements were performed using an XT-2000i analyzer (Sysmex Corp of America, Long Grove, IL, USA). This study was approved by the Ethics Committee of Ankara Yüksek İhtisas Education and Research Hospital, and informed consent was obtained from all study participants.

\section{Echocardiography}

Two-dimensional and Doppler echocardiography were performed. (Vivid 5 System, 2.5 MHz transducer, GEVingmed Ultrasound AS, Horten, Norway). All measurements were taken according to the American Society of Echocardiography guidelines. Mitral valve area was measured by using the pressure half-time method and planimetry of the mitral valve orifice from the short-axis view at the tip of the mitral leaflets. The mean transmitral diastolic pressure gradient was determined by using the Doppler method in the apical four-chamber view. Pulmonary arterial systolic pressure (PASP) was calculated by measuring the velocity of the tricuspid regurgitation jet. Severity of stenosis as defined by the American Society of Echocardiography and endorsed by the American College of Cardiology/American Heart Association valve disease guidelines are as follows:

1. Severe stenosis is associated with a mean transvalvular gradient $>10 \mathrm{mmHg}$, PASP $>50 \mathrm{mmHg}$, and valve area $<1.0 \mathrm{~cm}^{2}$.

2. Moderate stenosis is associated with a mean transvalvular gradient of 5-10 $\mathrm{mmHg}$, PASP pressures of $30-50 \mathrm{mmHg}$, and a valve area of $1.0-1.5 \mathrm{~cm}^{2}$.

3. Mild stenosis is associated with a mean transvalvular gradient of $<5 \mathrm{mmHg}$, PASP pressures $<30 \mathrm{mmHg}$, and a valve area $>1.5 \mathrm{~cm}^{2}$.

\section{Statistical analysis}

Data were analyzed with the SPSS software version 15.0 for Windows (SPSS Inc., Chicago, IL, USA). Categorical variables were presented as frequency and percentage. The $\chi^{2}$ test and Fisher's exact test were used to compare categorical variables. The Kolmogorov-Smirnov test was used to assess the distribution of continuous variables. Student's $t$-test was used for variables with normal distribution, and the values were presented as mean \pm standard deviation. Continuous variables without normal distribution were analyzed using Mann-Whitney $U$-test, and the values obtained were presented as median (50th) values and interquartile ranges (25th and 75th). One-way analysis of variance and Kruskal-Wallis test were used for parametric and nonparametric variables to compare tertiles, respectively. Multivariate logistic regression analysis was used to evaluate the independent association of the risk of severe RMS. Parameters with a $P$-value of less than 0.1 in univariate analysis were included in the model. The odds ratios (ORs) and 95\% confidence intervals (CIs) were calculated. A two-tailed $P$-value of $<0.05$ was considered statistically significant.

\section{Results}

A total of 300 consecutive patients were enrolled in the study. The mean age of the patients were $48.5 \pm 12.1$ years, and $64(21.3 \%)$ were male. The baseline characteristics are presented in Table 1. No significant differences were found in the presence of mitral regurgitation, hypertension, diabetes mellitus, and biochemical parameters. The patients 
Table I Comparison of the patient's baseline characteristics according to severity of mitral stenosis

\begin{tabular}{|c|c|c|c|c|}
\hline & $\begin{array}{l}\text { Severe MS (Group I), } \\
n=29\end{array}$ & $\begin{array}{l}\text { Moderate MS (Group 2), } \\
n=158\end{array}$ & $\begin{array}{l}\text { Mild MS (Group 3), } \\
n=1 / 3\end{array}$ & $\boldsymbol{P}$ \\
\hline Age, years & $48 \pm 14$ & $49 \pm 12$ & $48 \pm 12$ & 0.543 \\
\hline Male, n (\%) & 41 & 22 & 15 & 0.008 \\
\hline Ejection fraction, \% & $60(60-65)$ & $60(60-60)$ & $60(60-60)$ & 0.097 \\
\hline MVA, $\mathrm{cm}^{2}$ & $0.8 \pm 0.08$ & $1.3 \pm 0.2$ & $1.8 \pm 0.1$ & $<0.001$ \\
\hline Maximum transmitral gradient, $\mathrm{mmHg}$ & $22(19-26)$ & $15(13-18)$ & II (9-13) & $<0.001$ \\
\hline Mean transmitral gradient, $\mathrm{mmHg}$ & $12(11-14)$ & $7(6-9)$ & $5(4-7)$ & $<0.001$ \\
\hline Left atrium, $\mathrm{cm}$ & $5.0(4.9-5.3)$ & $5.0(4.0-5.0)$ & $4.0(4.0-5.0)$ & $<0.001$ \\
\hline Mitral regurgitation, $\%$ & & & & 0.149 \\
\hline 0 & 21 & 20 & 13 & \\
\hline I & 35 & 50 & 45 & \\
\hline 2 & 45 & 30 & 42 & \\
\hline PASP, mmHg & $58(45-67)$ & $39(33-43)$ & $33(30-38)$ & $<0.001$ \\
\hline Hemoglobin, g/dL & $13.8 \pm 1.4$ & $13.6 \pm 1.7$ & $13.7 \pm 1.5$ & 0.724 \\
\hline Hematocrit, \% & $42 \pm 4$ & $4 I \pm 4$ & $42 \pm 4$ & 0.526 \\
\hline WBC count, $\times 10^{3} / \mathrm{mm}^{3}$ & $7.9(7.1-8.4)$ & $7.0(6.0-8.0)$ & $7.0(6.0-8.0)$ & 0.085 \\
\hline Neutrophil count, $\times 10^{3} / \mathrm{mm}^{3}$ & $4.9 \pm 1.0$ & $4.5 \pm 1.3$ & $4.3 \pm 1.2$ & 0.025 \\
\hline Lymphocyte count, $\times 10^{3} / \mathrm{mm}^{3}$ & $1.9(1.5-2.3)$ & $2.0(1.6-2.3)$ & $2.1(1.7-2.5)$ & 0.031 \\
\hline $\mathrm{RDW}, \%$ & $14.5(|3.9-| 5.1)$ & | $3.8(|3.2-| 4.7)$ & | $3.7(|3.3-| 4.5)$ & 0.008 \\
\hline$M P V, f L$ & $10.4(9.4-11.0)$ & $9.2(8.6-9.7)$ & $9.1(8.7-9.7)$ & $<0.001$ \\
\hline Glucose, $\mathrm{mg} / \mathrm{dL}$ & $94(89-106)$ & $97(9 \mid-105)$ & $96(89-104)$ & 0.570 \\
\hline BUN & $26(23-32)$ & $28(24-34)$ & $27(24-34)$ & 0.600 \\
\hline Creatinine, $\mathrm{mg} / \mathrm{dL}$ & $0.86 \pm 0.20$ & $0.83 \pm 0.19$ & $0.83 \pm 0.16$ & 0.654 \\
\hline $\mathrm{LDL}, \mathrm{mg} / \mathrm{dL}$ & $118 \pm 29$ & $113 \pm 32$ & $110 \pm 30$ & 0.413 \\
\hline $\mathrm{HDL}, \mathrm{mg} / \mathrm{dL}$ & $43(4 \mid-5 I)$ & $47(4 I-58)$ & $47(4 \mid-55)$ & 0.322 \\
\hline Triglyceride, mg/dL & $176(100-205)$ & $125(83-187)$ & $116(86-180)$ & 0.171 \\
\hline Total cholesterol, mg/dL & $196 \pm 37$ & $191 \pm 42$ & $187 \pm 37$ & 0.557 \\
\hline NLR, $\mathrm{n}$ & $2.55(2.23-3.14)$ & $2.20(1.76-2.88)$ & $1.89(1.54-2.48)$ & $<0.001$ \\
\hline
\end{tabular}

Notes: Data are expressed as mean \pm standard deviation or count (percentage) for categorical variables. $P<0.05$ compared according to degree of mitral stenosis. Abbreviations: HDL, high density lipoprotein; LDL, low density lipoprotein; MPV, mean platelet volume; MS, mitral stenosis; MVA, mitral valve area; NLR, neutrophil to lymphocyte ratio; PASP, pulmonary artery systolic pressure; RDW, red cell distribution width; WBC, white blood cell; BUN, Blood urea nitrogen.

with severe RMS had significantly elevated NLR, mean platelet volume, and PASP values compared to patients with moderate and mild MS $(P<0.001, P<0.001, P<0.001$, respectively). Spearman's correlation analysis revealed a weak negative correlation between NLR and mitral valve area $\left(r_{\mathrm{s}}=-0.244, P<0.001\right)$ and a positive moderate correlation between NLR and mean transmitral gradient $\left(r_{\mathrm{s}}=0.277\right.$, $P<0.001)$ values.

After the initial evaluation, 187 patients with moderateto-severe RMS (Group 1) and 113 patients with mild RMS (Group 2) were reassessed (Table 2). The patients in Group 1

Table 2 Comparison of the NLR levels according to MVA $<1.5 \mathrm{~cm}$ or not

\begin{tabular}{llll}
\hline & $\begin{array}{l}\text { Moderate to severe } \\
\leq \mathrm{I} .5 \mathrm{~cm}^{2}, \mathrm{n}=187\end{array}$ & $\begin{array}{l}\text { Mild }>1.5 \mathrm{~cm}^{2}, \\
\mathrm{n}=\mathrm{I} \mathrm{I} 3\end{array}$ & $\boldsymbol{P}$ \\
\hline $\mathrm{NLR}$ & $2.24(\mathrm{I} .83-2.93)$ & $\mathrm{I} .89(\mathrm{I} .54-2.48)$ & $<0.00 \mathrm{I}$ \\
\hline
\end{tabular}

Notes: Data are expressed as mean \pm standard deviation or count (percentage) for categorical variables. $P<0.05$ compared with the moderate-to-severe mitral stenosis and mild mitral stenosis

Abbreviations: NLR, neutrophil to lymphocyte ratio; MPV, mean platelet volume. had higher NLR values. An univariate linear regression analysis for the relationship between severity of MS and other variables is shown in Table 3. Multivariate binary logistic regression analysis revealed that high levels of NLR, PSAP, and left atrium size were independent predictors of severe RMS (Table 3). RMS was associated with NLR (OR $=0.65$,

Table 3 Independent predictors of severity of mitral stenosis

\begin{tabular}{|c|c|c|c|c|c|c|}
\hline & \multicolumn{3}{|c|}{ Univariate analysis } & \multicolumn{3}{|c|}{ Multivariate analysis } \\
\hline & OR & $95 \% \mathrm{Cl}$ & $P$ & OR & $95 \% \mathrm{Cl}$ & $\mathbf{P}$ \\
\hline Male & 1.84 & $0.99-3.40$ & 0.051 & & & \\
\hline Left atrium & 0.28 & $0.18-0.44$ & $<0.001$ & 0.49 & $0.29-0.82$ & 0.006 \\
\hline PASP & 0.92 & $0.89-0.95$ & $<0.001$ & 0.94 & $0.90-0.97$ & 0.001 \\
\hline WBC & 0.94 & $0.80-1.10$ & 0.413 & & & \\
\hline Neutrophil & $0.8 \mathrm{I}$ & $0.67-0.99$ & 0.036 & & & \\
\hline Lymphocyte & 1.73 & I. $.4-2.6 \mathrm{I}$ & 0.010 & & & \\
\hline RDW & 0.89 & $0.73-1.09$ & 0.260 & & & \\
\hline MPV & 0.76 & $0.59-0.98$ & 0.034 & & & \\
\hline NLR & 0.56 & $0.41-0.77$ & $<0.001$ & 0.65 & $0.47-0.89$ & 0.008 \\
\hline
\end{tabular}

Abbreviations: $\mathrm{Cl}$, confidence interval; MPV, mean platelet volume; NLR, neutrophil to lymphocyte ratio; OR, odds ratio; PASP, pulmonary artery systolic pressure; RDW, red cell distribution width; WBC, white blood cell. 
95\% CI: $0.47-0.89, P=0.008)$, left atrium size $(\mathrm{OR}=0.49$, 95\% CI: $0.29-0.82, P=0.006)$, and PSAP values $(\mathrm{OR}=0.94$, 95\% CI: 0.90-0.97, $P<0.001)$.

Patients were divided into three tertiles based on the NLR levels. The relationship between RMS and NLR tertiles are presented in Table 4 and Figure 1. Moderate-to-severe RMS incidences were significantly higher among patients in the tertile 3 (OR $=2.8,95 \% \mathrm{CI}: 1.5-5.0, P<0.001)$.

\section{Discussion}

In the present study, we found that an increased NLR was independently associated with the degree of RMS.

Chronic RHD is one of the latest sequels of ARF occurring in approximately $30 \%$ of patients with rheumatic fever. ${ }^{11}$ In case of ARF, several inflammatory cells, such as neutrophils, macrophages, and $\mathrm{T}$ and $\mathrm{B}$ lymphocytes, infiltrate both the myocardium and the valves. The healing process of rheumatic carditis results in varying degrees of fibrosis and valve damage. RMS is a common manifestation of RHD. Inflammatory process plays a key role in RHD, and previous studies have shown that there is ongoing chronic inflammation in rheumatic mitral valve disease. In the previous studies, it was shown that levels of chronic inflammatory markers were higher in patients with rheumatic valve disease than control groups. ${ }^{12}$ Gölbasi et al reported that levels of C-reactive protein were higher in patients with rheumatic valve disease than in the control groups and they concluded that this could be a sign of chronic ongoing inflammation. ${ }^{13}$ Similarly, Alyan et al showed that C-reactive protein was significantly higher in patients with RMS than in the control group and independently correlated with the Wilkins valve score. ${ }^{14}$ Low-grade inflammation and oxygen radicals released by activated neutrophils can be shown in circulation in the coronary sinus. ${ }^{15-17}$ NLR, which can be derived from the white blood cell count, is a new marker of systemic inflammation. NLR provides an indicator of the inflammatory status that combines both neutrophils and lymphocytes. The main cause of increased NLR was probably the increased apoptosis of lymphocytes triggered by the increased inflammatory status in RMS. In a recent study, Öztürk et al reported

Table 4 The patients were divided into tertiles according to NLR

\begin{tabular}{llllll}
\hline & $\begin{array}{l}\text { Mild } \\
\text { MS }\end{array}$ & $\begin{array}{l}\text { Moderate- } \\
\text { severe MS }\end{array}$ & OR & 95\% Cl & P \\
\hline Tertile I, $\mathrm{n}=100$ & $46 \%$ & $25 \%$ & $\mathrm{I}$ & & \\
Tertile 2, $\mathrm{n}=100$ & $29 \%$ & $36 \%$ & 2.2 & $1.2-3.9$ & 0.007 \\
Tertile 3, $\mathrm{n}=100$ & $25 \%$ & $39 \%$ & 2.8 & $\mathrm{I} .5-5.0$ & $0.00 \mathrm{I}$ \\
\hline
\end{tabular}

Abbreviations: $\mathrm{MS}$, mitral stenosis; $\mathrm{Cl}$, confidence interval; OR, odds ratio; NLR, neutrophil to lymphocyte ratio.

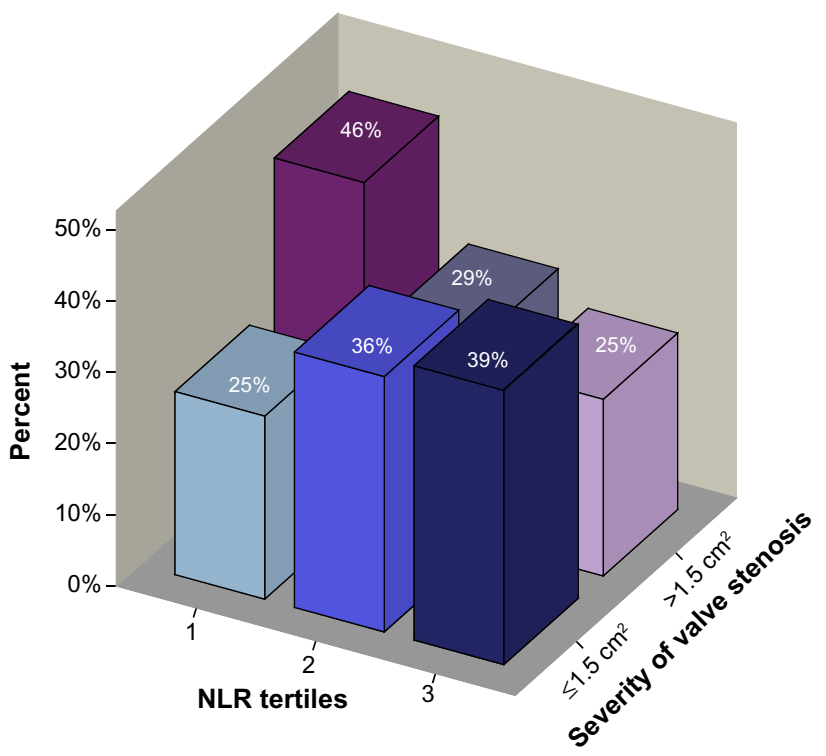

Figure I Patients were divided into three tertiles based on the NLR levels. Abbreviation: NLR, neutrophil to lymphocyte ratio.

that higher NLR was associated with spontaneous echocardiographic contrast in RMS. ${ }^{18}$ NLR is a new marker of inflammation that is associated with the severity of coronary artery disease, long-term mortality in patients undergoing primary percutaneous coronary intervention, and cardiac mortality in patients with stable coronary artery disease. ${ }^{7-9}$ In a recent study, it was reported that a high NLR was associated with thrombolysis failure in ST-elevation myocardial infarction patients treated with thrombolytic therapy. ${ }^{19}$ Horne et al reported that higher NLR was associated with worse clinical outcome in patients with ischemic heart disease without ST-elevation myocardial infarction. ${ }^{20}$ In addition to those studies, Cho et al report that NLR at 24 hours after admission is a predictor of mortality in patients with ST-elevation myocardial infarction who undergo percutaneous coronary intervention. ${ }^{21}$ Turak et al showed that a high NLR predicted in-hospital mortality and cerebrovascular events in patients with infective endocarditis. ${ }^{22}$

Although Akboğa et al found that NLR was significantly increased in patients with RMS than control groups, NLR did not reach statistical significance in MS groups. ${ }^{23}$ On the other hand, in a recent study, it was shown that high NLR predicted presence and severity of MS in patients with rheumatic mitral valve disease. ${ }^{24}$ However, Akboğa et al subdivided the RMS into mild-moderate and severe MS groups; we not only assessed mild, moderate and severe MS groups, but also reassessed mild and moderate-severe MS. Our study differs from the previous studies in that we evaluated the relationship between NLR and the degree of RMS. We subdivided the RMS into mild, moderate, and 
severe MS groups and showed that high NLR is associated with severity of MS.

Therefore, it may be an auxiliary parameter when used in combination with other parameters known to be associated with RMS.

Our study had several limitations. First, this was a retrospective study and included a relatively small number of patients. Second, we enrolled only patients with complete blood counts at admission. Therefore, the present results cannot be directly extrapolated to all patients with RHD. Third, there is no control group, and this is another limitation of the study.

\section{Conclusion}

NLR is a new inflammatory marker and a simple, rapid, and easily accessible prognostic parameter that can be associated with severity of RMS in patients with RHD.

\section{Acknowledgment}

The authors received no financial support for the research, authorship, and/or publication of this article.

\section{Disclosure}

The authors declare no potential conflicts of interest with respect to the research, authorship, and/or publication of this article.

\section{References}

1. Thakur JS, Negi PC, Ahluwalia SK, Vaidya NK. Epidemiological survey of rheumatic heart disease among school children in the Shimla Hills of Northern India: prevalence and risk factors. J Epidemiol Community Health. 1996;50:62-67.

2. Carapetis JR, Steer AC, Mulholland EK. The Current Evidence for the Burden of Group A Streptococcal Diseases (WHO/FCH/CAH/05.07). Geneva: World Health Organization; 2004.

3. Carapetis JR, Steer AC, Mulholland EK, Weber M. The global burden of group A streptococcal diseases. Lancet Infect Dis. 2005;5:685-94.

4. Essop MR, Nkomo VT. Rheumatic and nonrheumatic valvular heart disease: epidemiology, management, and prevention in Africa. Circulation. 2005;112:3584-3591.

5. Guilherme L, Kalil J. Rheumatic heart disease: molecules involved in valve tissue inflammation leading to the autoimmune process and anti-vaccine. Front Immunol. 2013;4:352.

6. Habeeb NM, Al Hadidi IS. Ongoing inflammation in children with rheumatic heart disease. Cardiol Young. 2011;21:334-339.

7. Shen XH, Chen Q, Shi Y, Li HW. Association of neutrophil/lymphocyte ratio with long-term mortality after ST elevation myocardial infarction treated with primary percutaneous coronary intervention. Chin Med J. 2010;123:3438-3443.
8. Papa A, Emdin M, Passino C, Michelassi C, Battaglia D, Cocci F. Predictive value of elevated neutrophil-lymphocyte ratio on cardiac mortality in patients with stable coronary artery disease. Clin Chim Acta. 2008;395:27-31.

9. Kaya H, Ertas F, Islamoglu Y, et al. Association between neutrophil to lymphocyte ratio and severity of coronary artery disease. Clin Appl Thromb Hemost. 2014;20:50-54.

10. Quinones MA, Otto CM, Stoddard M, Waggoner A, Zoghbi WA. Recommendations for quantification of Doppler echocardiography: a report from the Doppler quantification task force of the nomenclature and standards committee of the American Society of Echocardiography. JAm Soc Echocardiogr. 2002;15(2):167-184.

11. Rheumatic fever and rheumatic heart disease. World Health Organ Tech Rep Ser. 2004;923:1-122, backcover.

12. Davutoğlu V, Çelik A, Aksoy M. Contribution of selected serum inflammatory mediators to the progression of chronic rheumatic valve disease, subsequent valve calcification and NYHA functional class. $J$ Heart Valve Dis. 2005;14(2):251-256.

13. Gölbasi Z, Uçar O, Keles T, et al. Increased levels of high sensitive C-reactive protein in patients with chronic rheumatic valve disease: evidence of ongoing inflammation. Eur J Heart Fail. 2002;4(5): 593-595.

14. Alyan O, Metin F, Kacmaz F, et al. High levels of high sensitivity $\mathrm{C}$-reactive protein predict progression of chronic rheumatic mitral stenosis. J Thromb Thrombolysis. 2009;28(1):63-69.

15. Drakopoulou M, Toutouzas K, Stefanadi E, Tsiamis E, Tousoulis D, Stefanadis C. Association of inflammatory markers with angiographic severity and extent of coronary artery disease. Atherosclerosis. 2009;206:335-339.

16. Tanındı A, Şahinarslan A, Elbeg S, Cemri M. Relationship between MMP-1, MMP-9, TIMP-1, IL-6 and risk factors, clinical presentation, extent and severity of atherosclerotic coronary artery disease. Open Cardivasc Med J. 2011;5:110-116.

17. Ricevuti G, Mazzone A, De Servi S, Specchia G, Fratino P. New trends in coronary artery disease: the role of granulocyte activation. Atherosclerosis. 1989;78:261-265.

18. Öztürk D, Erturk M, Celık O, et al. The role of the neutrophil/ lymphocyte ratio in patients with rheumatic mitral stenosis as an indicator of spontaneous echocardiographic contrast. Kardiol Pol. 2014; 72(10):969-976

19. Baysal E, Cetin M, Yaylak B, et al. Roles of the red cell distribution width and neutrophil/lymphocyte ratio in predicting thrombolysis failure in patients with an ST-segment elevation myocardial infarction. Blood Coagul Fibrinolysis. 2015;26(3):274-278.

20. Horne BD, Anderson JL, John JM, et al. Which white blood cell subtypes predict increased cardiovascular risk? J Am Coll Cardiol. 2005;45(10):451638-451643.

21. Cho KH, Jeong MH, Ahmed K, et al. Value of early risk stratification using hemoglobin levels and neutrophil-to-lymphocyte ratio in patients with ST-elevation myocardial infarction undergoing primary percutaneous coronary intervention. Am J Cardiol. 2011;107:849-856.

22. Turak O, Özcan F, Işleyen A, et al. Usefulness of neutrophilto-lymphocyte ratio to predict in-hospital outcomes in infective endocarditis. Can J Cardiol. 2013;29(12):1672-1678.

23. Akboğa MK, Akyel A, Sahinarslan A, et al. Neutrophil-to-lymphocyte ratio is increased in patients with rheumatic mitral valve stenosis? Anadolu Kardiyol Derg. In press 2014.

24. Polat N, Yildiz A, Yuksel M, et al. Association of neutrophil-lymphocyte ratio with the presence and severity of rheumatic mitral valve stenosis. Clin Appl Thromb Hemost. 2014;20(8):793-798. 
Journal of Blood Medicine

\section{Publish your work in this journal}

The Journal of Blood Medicine is an international, peer-reviewed, open access, online journal publishing laboratory, experimental and clinical aspects of all topics pertaining to blood based medicine including but not limited to: Transfusion Medicine; Blood collection, Donor issues, Transmittable diseases, and Blood banking logistics; Immunohematology; Artificial and alternative

Submit your manuscript here: http://www.dovepress.com/Journal-of-blood-medicine-journal

blood based therapeutics; Hematology; Biotechnology/nanotechnology of blood related medicine; Legal aspects of blood medicine; Historical perspectives. The manuscript management system is completely online and includes a very quick and fair peer-review system. Visit http://www.dovepress.com/ testimonials.php to read real quotes from published authors. 